\title{
Pengaruh Citra Merek, Kualitas Produk dan Kualitas Pelayanan terhadap Keputusan Pembelian Cincau Station Ciputra World Surabaya
}

\author{
*Anis Ratih Mariana, Muslichah Erma Widiana, Enny Istanti \\ Program Studi Manajemen Fakultas Ekonomi dan Bisnis \\ Universitas Bhayangkara Surabaya, Indonesia
}

DOI: $10.46821 /$ benchmark.v1i1.217

\begin{abstract}
Abstrak
Tren di berbagai minuman kekinian terus bermunculan setiap harinya. Variannya pun berbedabeda membuat pembeli selalu ingin mencoba. Outlet minuman kekinian mudah ditemukan di mana saja. Mulai dari area kampus, hingga pusat perbelanjaan. Bisnis minuman semacam ini memang sedang menjamur mengingat respons positif dari masyarakat. Peneliti menggunakan pendekatan kuantitatif dengan pengumpulan data dengan menyebarkan kuesioner. Populasi dari penelitian ini adalah konsumen yang pernah membeli Cincau Station Ciputra World Surabaya sampel penelitian ini sebanyak 92 orang dengan metode slovin. Metode analisis pada penelitian ini menggunakan analisis regresi linier berganda dengan uji hipotesis yaitu uji normalitas, uji $\mathrm{F}$ (simultan), uji t (parsial) dan uji dominan. Hasil penelitian menunjukkan bahwa Citra Merek, Kualitas Produk, dan Kualitas Pelayanan berpengaruh signifikan secara simultan dan parsial terhadap Keputusan Pembelian. Variabel Citra Merek berpengaruh dominan terhadap Keputusan Pembelian Cincau Station Ciputra World Surabaya.

Kata Kunci: Citra Merek, Kualitas Produk, Kualitas Pelayanan dan Keputusan Pembelian.

Abstract

Trends in various contemporary drinks continue to emerge every day. The variants are also different to make buyers always want to try. Contemporary beverage outlets are easy to find anywhere. Starting from the campus area, to the shopping center. This kind of beverage business is mushrooming considering the positive response from the community. Researchers used a quantitative approach with data collection by distributing questionnaires. The population of this study were consumers who had bought Cincau Station Ciputra World Surabaya. The sample of this study was 92 people using the slovin method. The analytical method in this study uses multiple linear regression analysis with hypothesis testing, namely the normality test, $\mathrm{F}$ test (simultaneous), $\mathrm{t}$ test (partial) and dominant test. The results showed that Brand Image, Product Quality, and Service Quality had a significant simultaneous and partial effect on purchasing decisions. The Brand Image variable has a dominant influence on the Purchase Decision of Cincau Station Ciputra World Surabaya.
\end{abstract}

Keywords: Brand Image, Product Quality, Service Quality and Purchasing Decisions.

\section{PENDAHULUAN}

Pada era globalisasi seperti sekarang ini, Persaingan bisnis semakin ketat. Perusahaan harus mampu bersikap dan bertindak secara cepat dan tepat dalam menghadapi persaingan di lingkungan bisnis. Hal ini, dapat dilihat dengan adanya persaingan antar perusahaan satu dengan perusahaan lainnya untuk menarik perhatian konsumen. Artinya

*Corresponding Author:

Hal: $1-10$

Email: anisratih68@gmail.com 
konsumen tidak hanya membeli produk atau barang, tetapi yang dibeli adalah manfaat atau kegunaan produk tersebut (enny istanti, ruchan sanusi, 2020, 105).

Keadaan seperti ini membuat perusahaan harus mampu berfikir dalam merencanakan suatu strategi pemasaran yang tepat dan efektif. Strategi pemasaran tersebut bertujuan untuk mempertahankan kelangsungan suatu perusahaan serta pemasaran untuk mengembangkan perusahaan agar lebih besar dan terus berkembang. Salah satunya yaitu pada bisnis makanan dan minuman.

Keberadaan merek dianggap sebagai pilar bisnis sehingga dapat menarik minat konsumen untuk memakai produk tersebut. Setiap merek yang ditawarkan memiliki ciri khas masing-masing yang membedakan dengan produk pesaing. Citra merek merupakan segala asosiasi atau kesan yang muncul dibenak konsumen terkait dengan ingatannya mengenai suatu merek (Warusman, Untarini, 2016, 38).

Kualitas produk merupakan indikator terpenting bagi perusahaan, di karenakan kualitas produk sangat berpengaruh bagi konsumen. Semakin baik kualitas suatu produk, maka akan meningkatkan minat konsumen untuk memilih atau membeli produk tersebut. Kualitas produk adalah kemampuan suatu barang untuk memberikan hasil atau kinerja yang sesuai bahkan melebihi dari apa yang diinginkan pelanggan (Kotler, Keller, 2016,164).

Kualitas pelayanan merupakan tingkat keunggulan dan pengendalian untuk memenuhi keinginan pelanggan. Kualitas pelayanan adalah tingkat keunggulan yang diharapkan dan pengendalian atas tingkat keunggulan tersebut untuk memenuhi keinginan pelanggan (Tjiptono, 2016, 59).

Keputusan pembelian merupakan suatu unsur produk atau barang timbul karena adanya dorongan emosional dari dalam diri maupun pengaruh dari luar. Proses keputusan pembelian merupakan proses psikologis dasar yang memainkan peranan penting dalam memahami bagaimana konsumen benar-benar membuat keputusan pembelian mereka. Keputusan pembelian merupakan bagian dari perilaku konsumen. Perilaku konsumen yaitu studi tentang bagaimana individu, kelompok, dan organisasi memilih, membeli, menggunakan, dan bagaimana barang, jasa, ide atau pengalaman untuk memuaskan kebutuhan dan keinginan mereka. Keputusan pembelian juga merupakan patokan sebuah target pejualan sebuah perusahaan. (Kotler, Armstrong, 2016, 177).

\section{TINJAUAN PUSTAKA}

\section{Citra Merek}

Warusman, Untarini, 2016, 38 menyatakan bahwa citra merek merupakan segala asosiasi atau kesan yang muncul dibenak konsumen terkait dengan ingatannya mengenai suatu merek. Teori tersebut diperkuat dengan penelitian yang dilakukan oleh (Satrianing, adaming, 2019) pada penelitiannya yang berjudul "Pengaruh Citra Merek, Kualitas Produk, Dan Persepsi Harga Terhadap Keputusan Pembelian Pada Produk Ponsel Iphone (Studi Pada Mahasiswa Pendidikan Ekonomi Universitas Negeri Makassar)". Hasil penelitian menunjukan bahwa citra merek, kualitas produk, baik secara parsial maupun simultan berpengaruh positif dan signifikan terhadap keputusan pembelian, sementara persepsi harga berpengaruh negatif dan tidak signifikan, terhadap keputusan pembeliaan smartphone Iphone Mahasiswa Pendidikan Ekonomi Universitas Negeri Makassar. 


\section{Kualitas Produk}

Kualitas produk adalah kemampuan suatu barang untuk memberikan hasil atau kinerja yang sesuai bahkan melebihi dari apa yang diinginkan pelanggan (Kotler, Keller, 2016, 164). Teori tersebut diperkuat dengan penelitian yang dilakukan oleh (EDB, Situmorang, 2019) pada penelitiannya yang berjudul "Pengaruh Kualitas Pelayanan dan Kualitas Produk terhadap Keputusan Pembelian Konsumen pada Toko Amanda Brownies". Penelitian menunjukkan bahwa kualitas pelayanan dan kualitas produk baik secara parsial maupun simultan berpengaruh positif dan signifikan terhadap keputusan pembelian.

\section{Kualitas Pelayanan}

Tjiptiono tahun 2106,59 menyatakan bahwa kualitas pelayanan adalah tingkat keunggulan yang diharapkan dan pengendalian atas tingkat keunggulan tersebut untuk memenuhi keinginan pelanggan. Teori tersebut diperkuat dengan penelitian yang dilakukan oleh Siska, Farenzia tahun 2020 pada penelitiannya yang berjudul "Pengaruh Kualitas Pelayanan, Citra Merek Dan Promosi Terhadap Keputusan Pembelian Jasa Transportasi Online Grab". Penelitian menunjukkan bahwa kualitas pelayanan, citra merek dan promosi baik secara parsial maupun simultan berpengaruh positif dan signifikan terhadap keputusan pembelian.

\section{Keputusan Pembelian}

Keputusan pembelian merupakan bagian dari perilaku konsumen. Perilaku konsumen yaitu studi tentang bagaimana individu, kelompok, dan organisasi memilih, membeli, menggunakan, dan bagaimana barang, jasa, ide atau pengalaman untuk memuaskan kebutuhan dan keinginan mereka. Keputusan pembelian juga merupakan patokan sebuah target pejualan sebuah perusahaan (Kotler, Armstrong, 2016, 177).

\section{Hipotesis Penelitian :}

$\mathrm{H}_{1}$ : Bahwa variabel citra merek, kualitas produk dan kualitas pelayanan secara simultan berpengaruh signifikan terhadap keputusan pembelian pada cincau station Ciputra World Surabaya.

$\mathrm{H}_{2}$ : Bahwa variabel citra merek, kualitas produk dan kualitas pelayanan secara parsial berpengaruh signifikan terhadap keputusan pembelian pada cincau station Ciputra World Surabaya.

$\mathrm{H}_{3}$ : Bahwa variabel citra merek berpengaruh dominan terhadap keputusan pembelian cincau station Ciputra World Surabaya.

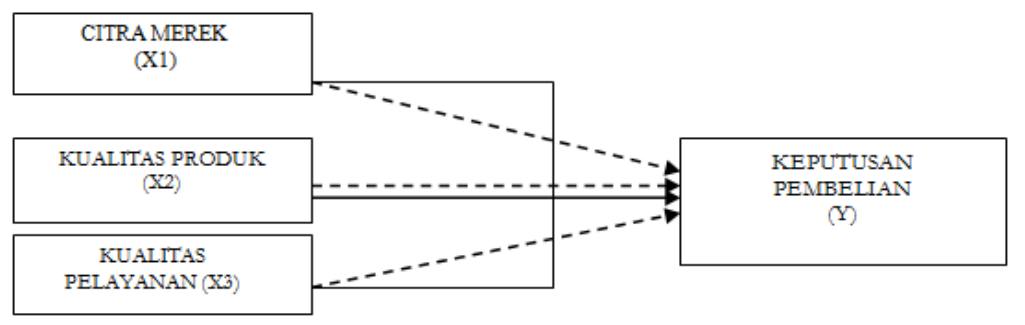

Gambar 1

Kerangka Konseptual 
METODE PENELITIAN

Lokasi Dan Waktu Penelitian

Lokasi Cincau station Ciputra World Surabaya berada di Food Court Ciputra World, Lantai 3, Food Wave, JL. Mayjen Sungkono No.89, Gunung Sari, Dukuh Pakis, Surabaya, Jawa Timur. Waktu penelitian dilakukan pada bulan Maret 2021 - Juli 2021 dilakukan sampai dengan data yang diperlukan sudah lengkap sesuai dengan kebutuhan peneliti.

\section{Pendekatan Penelitian}

Pendekatan dilakukan dengan pendekatan kuantitatif yang merupakan data yang diperoleh dari hasil perhitungan dan pengukuran. Data yang digunakan dalam penelitian ini adalah data primer.

\section{Metode Pengumpulan Data}

Pengumpulan data yang digunakan dalam penelitian ini adalah wawancara, yaitu secara langsung memperoleh dari data konsumen yang pernah membeli cincau station Ciputra World Surabaya.

\section{Analisis Data}

Analisis data dalam penelitian ini adalah metode analisis data kuantitatif dengan menggunakan alat uji data program Statistical Panckage for Social Sciences (SPSS). Kemudian untuk uji yang digunakan yaitu uji validitas, reliabilitas, regresi linier berganda, koefisien determinasi, normalitas, uji F, uji t dan pembuktian dominan.

\section{HASIL ANALISIS DAN PEMBAHASAN}

\section{Uji Validitas}

Hasil perhitungan uji validitas terhadap seluruh butir kuesioner semuanya valid. Item kuesioner dinyatakan valid karena $r$ hitung untuk semua item kuesioner lebih besar dari $r$ tabel pada taraf signifikan $0,05(5 \%)$ yaitu sebesar 0,2050 . Dari hasil uji validitas dapat dinyatakan bahwa seluruh pertanyaan dalam kuesioner dinyatakan valid (Tabel 1).

\section{Uji Reliabilitas}

Berdasarkan hasil uji reliabilitas dapat diketahui bahwa hasil Cronbach Alpha setiap variabel lebih dari standar Cronbach $A \not p h a$ yang disyaratkan yaitu 0,60. Maka variabel citra merek, kualitas produk, dan kualitas pelayanan terhadap keputusan pembelian dinyatakan reliabel (Tabel 2).

\section{Uji Analisis Regresi Linier Berganda}

Berdasarkan hasil uji pada tabel 3 dapat diketahui naik turunya suatu variabel yang artinya jika variabel bebas citra merek, kualitas produk dan kualitas pelayanan mengalami kenaikan satu satuan maka variabel terikat keputusan pembelian akan mengalami kenaikan.

\section{Uji Koefisien Determinasi}

Berdasarkan tabel 4, dapat diketahui nilai $\mathrm{R}$ Square sebesar 0,537 atau 53,7\%. Maka dapat disimpulkan bahwa adanya pengaruh yang kuat antara variabel citra merek (X1), kualitas produk (X2) dan kualitas pelayanan (X3) terhadap keputusan pembelian (Y). 


\begin{tabular}{|c|c|c|c|c|c|}
\hline & $\mathrm{Uj}$ & $\begin{array}{l}\text { Tabel } \\
\text { Valid }\end{array}$ & & & \\
\hline Variabel & $\begin{array}{l}\text { Variabe } \\
\text { (r-bitung }\end{array}$ & & r-tabel & Sig. & Keterangan \\
\hline & $\mathrm{X} 1.1$ & 0,729 & & 0,000 & Valid \\
\hline Variabel Citra Merek (X1) & $\mathrm{X} 1.2$ & 0,881 & & 0,000 & Valid \\
\hline & $\mathrm{X} 1.3$ & 0,749 & & 0,000 & Valid \\
\hline & $\mathrm{X} 1.4$ & 0,691 & & 0,000 & Valid \\
\hline & $\mathrm{X} 1.5$ & 0,660 & & 0,000 & Valid \\
\hline & $\mathrm{X} 2.1$ & 0,809 & & 0,000 & Valid \\
\hline Variabel Kualitas Produk (X2) & $\mathrm{X} 2.2$ & 0,850 & & 0,000 & Valid \\
\hline & $\mathrm{X} 2.3$ & 0,553 & & 0,000 & Valid \\
\hline & X.2.4 & 0,735 & & 0,000 & Valid \\
\hline & $\mathrm{X} 2.5$ & 0,739 & 0,2050 & 0,000 & Valid \\
\hline & X3.1 & 0,603 & & 0,000 & Valid \\
\hline Variabel Kualitas Pelayanan (X3) & $\mathrm{X} 3.2$ & 0,726 & & 0,000 & Valid \\
\hline & $\mathrm{X} 3.3$ & 0,606 & & 0,000 & Valid \\
\hline & X3.4 & 0,624 & & 0,000 & Valid \\
\hline & $\mathrm{X} 3.5$ & 0,597 & & 0,000 & Valid \\
\hline & Y.1 & 0,615 & & 0,000 & Valid \\
\hline Variabel Keputusan Pembelian (Y) & Y.2 & 0,585 & & 0,000 & Valid \\
\hline & Y.3 & 0,745 & & 0,000 & Valid \\
\hline & Y. 4 & 0,668 & & 0,000 & Valid \\
\hline & Y. 5 & 0,626 & & 0,000 & Valid \\
\hline
\end{tabular}

Sumber: Data Diolah, 2021

Tabel 2

Uji Reliabilitas

\begin{tabular}{lrrcc}
\hline \multicolumn{1}{c}{ Variabel } & Nilai Alpha Croncbach & Tanda & $\begin{array}{c}\text { Minimal Cronbach } \\
\text { alpha }\end{array}$ & Keterangan \\
\hline Citra Merek (X1) & .808 & $>$ & 0,6 & Reliabel \\
Kualitas produk (X2) & $.809>$ & 0,6 & Reliabel \\
Kualitas pelayanan (X3) & $.606>$ & 0,6 & Reliabel \\
Keputusan pembelian (Y) & .651 & $>$ & 0,6 & Reliabel \\
\hline
\end{tabular}

Sumber: Data Diolah, 2021

Tabel 3

Uji Regresi Linier Berganda Coefficients $^{\mathrm{a}}$

\begin{tabular}{|c|c|c|c|c|c|c|c|}
\hline \multirow[b]{2}{*}{ Model } & \multicolumn{2}{|c|}{$\begin{array}{l}\text { Unstandardized } \\
\text { Coefficients }\end{array}$} & $\begin{array}{l}\text { Standardized } \\
\text { Coefficients }\end{array}$ & \multirow[b]{2}{*}{ T } & \multirow[b]{2}{*}{ Sig. } & \multicolumn{2}{|c|}{ Collinearity Statistics } \\
\hline & B & $\begin{array}{l}\text { Std. } \\
\text { Error }\end{array}$ & Beta & & & Tolerance & VIF \\
\hline 1 (Constant) & 610 & 2,434 & & 251 & 803 & & \\
\hline Citra merek & ,440 & ,068 & , 486 & 6,483 & 000 & ,934 & 1,071 \\
\hline Kualitas produk & ,355 & ,064 & , 416 & 5,552 & ,000 & ,937 & 1,067 \\
\hline Kualitaspelayanan & ,203 & ,078 & , 189 & 2,594 & ,011 & ,995 & 1,005 \\
\hline
\end{tabular}

Sumber: Data Diolah, 2021 


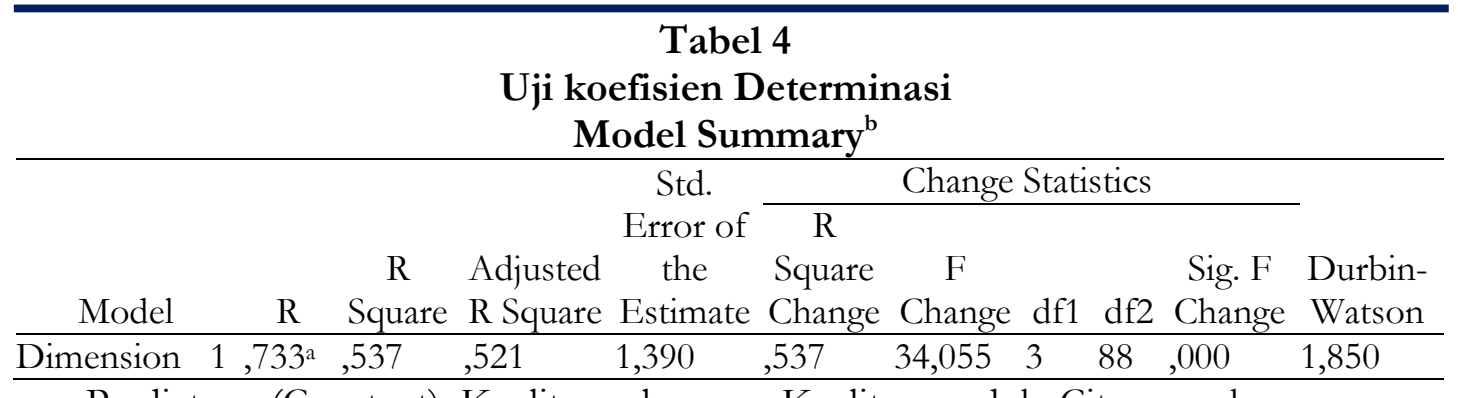

a. Predictors: (Constant), Kualitas pelayanan, Kualitas produk, Citra merek

b. Dependent Variable: Keputusan pembelian

Sumber: Data Diolah, 2021

\section{Tabel 5}

\section{Uji normalitas}

One-Sample Kolmogorov-Smirnov Test

\begin{tabular}{llr}
\hline & & Unstandardized Residual \\
\hline Normal Parameters & & 92 \\
& Mean &, 0000000 \\
Most Extreme Differences & Std. Deviation & 1,36668429 \\
& Absolute &, 116 \\
& Positive &, 086 \\
& Negative &,- 116 \\
Kolmogorov-Smirnov Z & & 1,113 \\
Asymp. Sig. (2-tailed) & &, 168 \\
\hline
\end{tabular}

a. Test distribution is Normal

b. Calculated from data

Sumber: Data Diolah, 2021

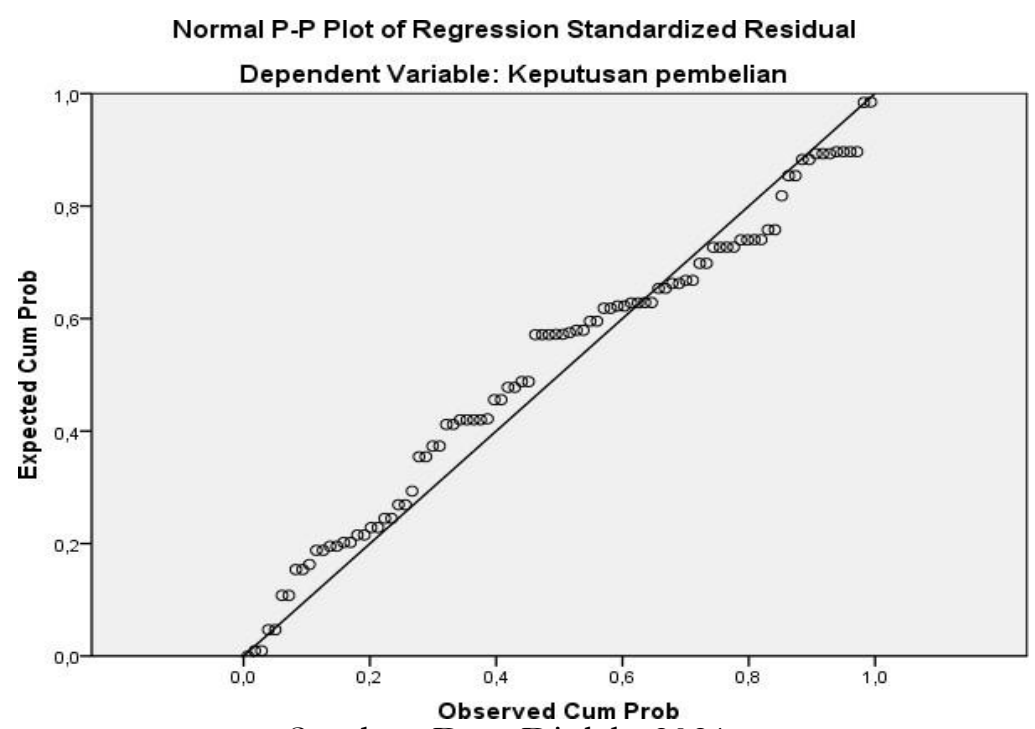

Sumber: Data Diolah, 2021

Gambar 2

Normal Probabiliti Plot 


\section{Uji Normalitas}

Tabel 5 diperoleh nilai asymp.sig sebesar 0,168 (0,168>0,05). Sehingga dapat disimpulkan bahwa semua data berdistribusi normal. Untuk mengetahui normal atau tidaknya menggunakan Plot of regression Standardized residual. Data dinyatakan berdistribusi normal jika sebaran data membentuk titik-titik yang mendekati garis diagonal.

Hasil uji normalitas pada penelitian ini menunjukkan bahwa grafik normal probability plot yang mensyaratkan bahwa data bersebaran data harus berada di wilayah garis diagonal dan mengikuti arah garis diagonal. Berdasarkan gambar 2, maka hasil ini memenuhi syarat normal probability plot. Artinya data dalam penelitian ini populasi yang berdistribusi normal.

\section{Uji Simultan ( Uji F)}

Dari hasil pengujian yang terdapat pada tabel 6 , maka didapat nilai $F_{\text {tabel }}$ sebesar 2,71. Oleh karena itu $\mathrm{F}_{\text {hitung }}$ 34,055 lebih besar dari $\mathrm{F}_{\text {tabel }}$ 2,71 dan tabel diatas juga menunjukkan nilai sig $=0,000$ yang lebih kecil dari $\alpha=0,05$ maka dari hasil tersebut dapat dinyatakan bahwa $\mathrm{H}_{0}$ ditolak dan $\mathrm{H}_{1}$ diterima, artinya variabel bebas citra merek, kualitas produk dan kualitas pelayanan secara simultan berpengaruh signifikan terhadap variabel terikat keputusan pembelian.

\section{Uji Parsial (Uji t)}

Berdasarkan tabel 7 diperoleh $t_{\text {hitung }}$ sebesar 6,483 hal ini menunjukkan $t_{\text {hitung }} 6,483$ lebih besar dari $t_{\text {tabel }}$ 1,662. uji $t$ diperoleh $t_{\text {hitung }}$ sebesar 5,552 hal ini menunjukkan $t_{\text {hitung }} 5,552$ lebih besar dari $t_{\text {tabel }}$ 1,662. tabel uji t diperoleh $t_{\text {hitung }}$ sebesar 2,594 hal ini menunjukkan $t_{\text {hitung }} 2,594$ lebih besar dari $t_{\text {tabel }}$ 1,662. Dari kesimpulan 3 variabel diatas dapat disimpulkan bahwa variabel citra merek, kualitas produk dan kualitas pelayanan secara parsial berpengaruh signifikan dan positif terhadap keputusan pembelian cincau station Ciputra World Surabaya yang berarti Hi diterima dan Ho ditolak.

\section{Pembuktian Uji Dominan}

Berdasarkan Tabel 8 dapat diperoleh nilai standardized coefficients beta untuk variabel citra merek sebesar 0,486, variabel kualitas produk sebesar 0,416 dan variabel kualitas pelayanan sebesar 0,189. Berdasarkan hasil pengujian tersebut maka dapat dinyatakan bahwa citra merek berpengaruh dominan terhadap keputusan pembelian dengan hasil nilai standardized coefficients beta untuk variabel citra merek sebesar 0,440.

\begin{tabular}{lrrrrrr}
\multicolumn{7}{c}{ Tabel 6 } \\
Uji Simultan (Uji F) \\
ANOVA $^{\mathbf{b}}$
\end{tabular}

a. Predictors: (Constant), Kualitas pelayanan, Kualitas produk, Citra merek

b. Dependent Variable: Keputusan pembelian

Sumber: Data Diolah, 2021 


\begin{tabular}{|c|c|c|c|c|c|c|c|}
\hline \multirow[b]{3}{*}{ Model } & \multicolumn{5}{|c|}{$\begin{array}{c}\text { Tabel } 7 \\
\text { Uji Parsial (Uji t) } \\
\text { Coefficients }^{\mathrm{a}}\end{array}$} & & \\
\hline & \multicolumn{2}{|c|}{$\begin{array}{l}\text { Unstandardized } \\
\text { Coefficients }\end{array}$} & $\begin{array}{l}\text { Standardized } \\
\text { Coefficients }\end{array}$ & \multirow[b]{2}{*}{$\mathrm{t}$} & \multirow[b]{2}{*}{ Sig. } & \multicolumn{2}{|c|}{ Collinearity Statistics } \\
\hline & $\mathrm{B}$ & Std. Error & Beta & & & Tolerance & VIF \\
\hline 1 (Constant) & ,610 & 2,434 & & ,251 & ,803 & & \\
\hline Citra merek &, 440 & ,068 & ,486 & 6,483 &, 000 & ,934 & 1,071 \\
\hline Kualitas produk & ,355 &, 064 & ,416 & 5,552 & ,000 & 937 & 1,067 \\
\hline $\begin{array}{l}\text { Kualitas } \\
\text { pelayanan }\end{array}$ & ,203 &, 078 & ,189 & 2,594 &, 011 & ,995 & 1,005 \\
\hline
\end{tabular}

a. Dependent Variable: Keputusan pembelian

Sumber: Data Diolah, 2021

\section{Tabel 8}

Uji Dominan

Coefficients $^{a}$

\begin{tabular}{|c|c|c|c|c|c|c|c|}
\hline \multirow[b]{2}{*}{ Model } & \multicolumn{2}{|c|}{$\begin{array}{c}\text { Unstandardized } \\
\text { Coefficients }\end{array}$} & \multirow{2}{*}{$\begin{array}{c}\begin{array}{c}\text { Standardized } \\
\text { Coefficients }\end{array} \\
\text { Beta }\end{array}$} & \multirow[b]{2}{*}{$\mathrm{t}$} & \multirow[b]{2}{*}{ Sig. } & \multicolumn{2}{|c|}{ Collinearity Statistics } \\
\hline & $\mathrm{B}$ & Std. Error & & & & Tolerance & VIF \\
\hline 1 (Constant) & ,610 & 2,434 & & ,251 & ,803 & & \\
\hline Citra merek &, 440 & ,068 & ,486 & 6,483 & ,000 & ,934 & 1,071 \\
\hline $\begin{array}{l}\text { Kualitas } \\
\text { produk }\end{array}$ & ,355 &, 064 & ,416 & 5,552 & ,000 & 937 & 1,067 \\
\hline $\begin{array}{l}\text { Kualitas } \\
\text { pelayanan }\end{array}$ & 203 & ,078 & ,189 & 2,594 & ,011 & 995 & 1,005 \\
\hline
\end{tabular}

a. Dependent Variable: Keputusan pembelian

Sumber: Data Diolah, 2021

\section{Pembahasan}

Pengaruh Secara Simultan Citra Merek (X1), Kualitas Produk (X2) Dan Kualitas Pelayanan (X3) Terhadap Keputusan Pembelian (Y)

Hasil analisis data yang sudah diolah membuktikan bahwa variabel citra merek, kualitas produk dan kualitas pelayanan berpengaruh secara simultan terhadap keputusan pembelian. Hasil dari tanggapan 92 responden yang telah di olah menggunakan SPSS dengan hasil penelitian menghasilkan bahwa nilai $\mathrm{F}_{\text {hitung }}$ sebesar 34,055 lebih besar dari pada $F_{\text {tabel }}$ 2,71 dengan signifikan 0,000. Dengan demikian dapat dinyatakan bahwa setiap peningkatan nilai variabel citra merek, kualitas produk dan kualitas pelayanan secara bersama-sama, akan mempengaruhi keputusan pembelian cincau station di mall Ciputra World Surabaya.

\section{Pengaruh Secara Parsial Citra Merek Terhadap Keputusan Pembelian}

Berdasarkan analisis membuktikan bahwa variabel citra merek berpengaruh secara parsial terhadap keputusan pembelian cincau station Ciputra World Surabaya. Hasil dari tanggapan 92 responden yang telah diolah menggunakan SPSS dengan hasil penelitian menghasilkan Koefisien bernilai positif yaitu 0,440 variabel citra merek terhadap 
keputusan pembelian akan menghasilkan nilai Beta sebesar 0,486 yang didapat hasil dari nilai $\mathrm{T}_{\text {hitung }}$ pada variabel citra merek sebesar $6,483>\mathrm{T}_{\text {tabel }} 1,662$ dengan taraf signifikan $0,000<0,05$. Artinya terdapat pengaruh signifikan antara variabel citra merek terhadap keputusan pembelian cincau station Ciputra World Surabaya.

\section{Pengaruh Secara Parsial Kualitas Produk Terhadap Keputusan Pembelian}

Berdasarkan analisis membuktikan bahwa variabel kualitas produk berpengaruh secara parsial terhadap keputusan pembelian cincau station Ciputra World Surabaya. Hasil dari tanggapan 92 responden yang telah diolah menggunakan SPSS dengan hasil penelitian menghasilkan Koefisien bernilai positif yaitu 0,355, variabel kualitas produk terhadap keputusan pembelian akan menghasilkan nilai Beta sebesar 0,416 yang didapat hasil dari nilai $\mathrm{T}_{\text {hitung }}$ pada variabel kualitas produk sebesar 5,552> $\mathrm{T}_{\text {tabel }}$ 1,662 dengan taraf signifikan $0,000<0,05$. Artinya terdapat pengaruh signifikan antara variabel kualitas produk terhadap keputusan pembelian cincau station Ciputra World Surabaya.

\section{Pengaruh Secara Parsial Kualitas Pelayanan Terhadap Keputusan Pembelian}

Berdasarkan analisis membuktikan bahwa variabel kualitas pelayanan berpengaruh secara parsial terhadap keputusan Pembelian cincau station Ciputra World Surabaya. Hasil dari tanggapan 92 responden yang telah diolah menggunakan SPSS dengan hasil penelitian menghasilkan Koefisien bernilai positif yaitu 0,203, variabel kualitas pelayanan terhadap keputusan pembelian akan menghasilkan nilai Beta sebesar 0,189 yang didapat hasil dari nilai $\mathrm{T}_{\text {hitung }}$ pada variabel kualitas pelayanan sebesar $2,594>\mathrm{T}_{\text {tabel }} 1,662$ dengan taraf signifikan $0,011<0,05$. Artinya terdapat pengaruh signifikan antara variabel kualitas pelayanan terhadap keputusan pembelian cincau station Ciputra World Surabaya.

Variabel Bebas yang Berpengaruh Dominan terhadap Keputusan Pembelian. Berdasarkan analisis membuktikan bahwa variabel citra merek berpengaruh paling dominan terhadap keputusan pembelian cincau station Ciputra World Surabaya. Hasil penelitian variabel citra merek berpengaruh paling dominan terhadap keputusan pembelian dengan hasil nilai standardized coefficients beta sebesar 0,486. Hal tersebut yang berarti citra merek sangat berpengaruh positif terhadap keputusan pembelian cincau station Ciputra World Surabaya, Sehingga dapat dinyatakan bahwa citra merek dapat menarik perhatian konsumen agar dapat memutuskan pembelian mereka.

\section{SIMPULAN DAN SARAN}

Dari hasil penelitian menggunakan Uji F citra merek, kualitas produk dan kualitas pelayanan dengan demikian variabel bebas secara simultan berpengaruh signifikan terhadap variabel terikat. Dari hasil penelitian menggunakan Uji t citra merek secara parsial berpengaruh signifikan terhadap variabel keputusan pembelian. Kualitas produk secara parsial berpengaruh signifikan terhadap variabel keputusan pembelian. Kualitas pelayanan secara parsial berpengaruh signifikan terhadap variabel keputusan pembelian. Berdasarkan uji dominan dapat diketahui bahwa citra merek mempunyai standartdized of coefficient beta atau $\beta$ (beta) terbesar 0,486 yang merupakan nilai terbesar diantara variabel-variabel bebas yang lain. Sehingga dapat disimpulkan citra merek berpengaruh dominan terhadap keputusan pembelian cincau station Ciputra World Surabaya. 
DAFTAR PUSTAKA

Satriani A. Pengaruh Citra Merek, Kualitas Produk, Dan Persepsi Harga Terhadap Keputusan Pembelian Pada Produk Ponsel Iphone (Studi Pada Mahasiswa Pendidikan Ekonomi Universitas Negeri Makassar ). Published online 2019.

Amalia N. Pengaruh Citra Merek, Harga Dan Kualitas Produk Terhadap Keputusan Pembelian (Studi Kasus Pada Konsumen Mie Endess Di Bangkalan). J Stud Manaj dan Bisnis. 2019;6(2):96-104.

Arli D, Cherrier H, Tjiptono F. God blesses those who wear Prada: Exploring the impact of religiousness on attitudes toward luxury among the youth of Indonesia. Mark Intell Plan. Published online 2016.

Br Situmorang ED, Gultom R, Nadapdap K, Sihite M. Pengaruh Kualitas Pelayanan Dan Kualitas Produk Terhadap Keputusan Pembelian Konsumen Pada Toko Amanda Brownies. J Ris Manaj Sekol Tinggi Ilmu Ekon Widya Wiwaha Progr Magister Manaj. 2019;6(1):40-51. doi:10.32477/jrm.v6i1.334

Enny Istanti, Ruchan Sanusi ADG. Impacts of Price, Promotion and Go Food Consumer Satisfaction in Faculty of Economic and Business Students of Bhayangkara University Surabaya. Ekspektra J Bisnis dan Manaj. 2020;4(2):104-120. doi:10.25139/ekt.v4i2.3134.

Farenzia S, Raymond R. Pengaruh Kualitas Pelayanan, Citra Merek dan Promosi terhadap Keputusan Pembelian Jasa Transportasi Online Grab. J Manaj Bisnis. 2020;33(1):109-122.

Gregorius C, Fandy T. Service, Quality \& Satisfaction. In: Edisi Empat. Yogyakarta: ANDI; 2016.

Kotler P, Armstrong G. Published online 2016.

Kotler P, Keller KL. A Framework for Marketing Management. Pearson Boston, MA; 2016.

Satriani A. Pengaruh Citra Merek, Kualitas Produk, Dan Persepsi Harga Terhadap Keputusan Pembelian Pada Produk Ponsel Iphone (Studi Pada Mahasiswa Pendidikan Ekonomi Universitas Negeri Makassar ). Published online 2019.

Warusman JD. Pengaruh Citra Merek dan Kepercayaan Merek terhadap Loyalitas Pelanggan (Studi Pada Anggota Komunitas Sepeda Motor Honda Vario 125cc di Surabaya). J Ilmu Manaj. 2016;4(2). 